Article

\title{
Activity-Integrated Hidden Markov Model to Predict Calving Time
}

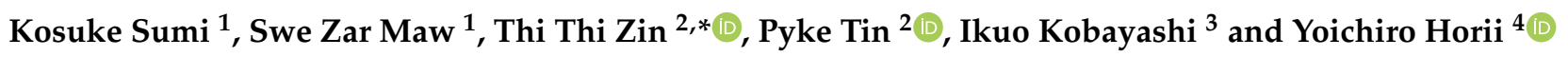 \\ 1 Interdisciplinary Graduate School of Agriculture and Engineering, University of Miyazaki, \\ Miyazaki 889-2192, Japan; hc11093@student.miyazaki-u.ac.jp (K.S.); \\ z3t1802@student.miyazaki-u.ac.jp (S.Z.M.) \\ 2 Graduate School of Engineering, University of Miyazaki, Miyazaki 889-2192, Japan; pyketin11@gmail.com \\ 3 Field Science Center, Faculty of Agriculture, University of Miyazaki, Miyazaki 889-2192, Japan; \\ ikuokob@cc.miyazaki-u.ac.jp \\ 4 Center for Animal Disease Control, University of Miyazaki, Miyazaki 889-2192, Japan; \\ horii@cc.miyazaki-u.ac.jp \\ * Correspondence: thithi@cc.miyazaki-u.ac.jp
}

Citation: Sumi, K.; Maw, S.Z.; Zin, T.T.; Tin, P.; Kobayashi, I.; Horii, Y. Activity-Integrated Hidden Markov Model to Predict Calving Time. Animals 2021, 11, 385. https://doi.org/10.3390/ani11020385

Academic Editors: Maria Caria and Giuseppe Todde

Received: 3 December 2020

Accepted: 29 January 2021

Published: 3 February 2021

Publisher's Note: MDPI stays neutral with regard to jurisdictional claims in published maps and institutional affiliations.

Copyright: (C) 2021 by the authors Licensee MDPI, Basel, Switzerland. This article is an open access article distributed under the terms and conditions of the Creative Commons Attribution (CC BY) license (https:// creativecommons.org/licenses/by/ $4.0 /)$.
Simple Summary: Dairy cows are known to become more active during the time calving approaches. Dairy farms provide individual calving pens to monitor the behavior of pregnant cows. Frequent posture changes such as alternating between lying and standing are good indicators that calving is imminent. In this paper, we aimed to determine how using these behavior changes or activities could help predict calving time. The activity monitoring video cameras in this study were located at a top corner of the calving pens so that the whole pens are visible. By processing the collected video sequences, the activities of pregnant cows three days before the calving were modeled in a Hidden Markov Model to predict the time when the calving event occurs. The experimental results show that the proposed method has promise.

Abstract: Accurately predicting when calving will occur can provide great value in managing a dairy farm since it provides personnel with the ability to determine whether assistance is necessary. Not providing such assistance when necessary could prolong the calving process, negatively affecting the health of both mother cow and calf. Such prolongation could lead to multiple illnesses. Calving is one of the most critical situations for cows during the production cycle. A precise video-monitoring system for cows can provide early detection of difficulties or health problems, and facilitates timely and appropriate human intervention. In this paper, we propose an integrated approach for predicting when calving will occur by combining behavioral activities extracted from recorded video sequences with a Hidden Markov Model. Specifically, two sub-systems comprise our proposed system: (i) Behaviors extraction such as lying, standing, number of changing positions between lying down and standing up, and other significant activities, such as holding up the tail, and turning the head to the side; and, (ii) using an integrated Hidden Markov Model to predict when calving will occur. The experiments using our proposed system were conducted at a large dairy farm in Oita Prefecture in Japan. Experimental results show that the proposed method has promise in practical applications. In particular, we found that the high frequency of posture changes has played a central role in accurately predicting the time of calving.

Keywords: calving; prediction; Hidden Markov Model; behavior changes

\section{Introduction}

The calving process is one of the most stressful and painful experiences for a dairy cow to deal with during the production cycle. Dystocia [1] is a prolonged, abnormal, or difficult birth, which is a serious issue for dairy farmers because it can cause economic 
loss, and dealing with it is labor-intensive. Such difficulties result from prolonged spontaneous calving or prolonged or severe assisted extraction. Therefore, farm management personnel require accurate and reliable systems for predicting when calving will occur, helping decide when to provide assistance. Naturally, cows are vulnerable when calving, due to the changes and stress they experience. Predicting the exact time of calving, as well as specific calving behaviors, requires continuous monitoring. Precision cow monitoring technologies such as image processing techniques can provide visual information for the assessment of calving behaviors, and help minimize difficulties. According to some research findings [1-3], the rate of mortality due to difficult calving reaches $35 \%$ at the international level. Jensen described that managing the calving process is the most important area of dairy research, specifically for preventing long-term illness [4]. Most dairy farmers and observers know that cows become restless immediately before calving. According to some previous research works [5-7], this restlessness is characterized by irregular behavior such as frequent changes in posture, holding up the tail, turning the head backwards, lying, standing, and bouts of frequently changing position between lying down and standing up. In addition, changes in the behavioral patterns of dairy cows have been used by farmers and animal doctors to detect poor health, and determine phases in the estrus cycle. Among the many behavior patterns, those of lying down, and bouts of changing position between lying down and standing up, rank high as subjects of study [6-8]. However, even after years of research, these behaviors are not fully understood. Exactly how these behaviors relate to the calving process, and to other aspects of dairy farming, must be investigated.

In this paper, we integrate into a Hidden Markov Model (HMM) the activities of lying down, standing up, bouts of frequently changing position between lying down and standing up, as well as the proportion of time spent in changing posture, and then perform a modified Viterbi Algorithm to predict when calving will occur.

In order to predict when calving begins, different researchers have proposed various methods and technologies, including monitoring through the use of wearable sensors [9-12], observing changes in body temperature [13], and a variety of techniques using biosensors for monitoring tail elevations [14,15]. Mee and English discuss methods and devices developed for calving prediction, presenting a good summary of the current status of methodologies and technologies in this area of research [5].

Among various findings, the methods can be categorized into three groups. They are the prediction of calving time based on (i) hormonal changes, (ii) clinical signs, and (iii) behavioral changes just before calving. According to Mee and English, the systems based on behavioral changes seem to be the most promising, since significant changes can be monitored within a day of calving. However, predicting the exact starting time is still difficult.

Recently, as discussed in [16], the authors described rumination and feeding behavior around calving and the time spent on these behaviors are monitored and analyzed. The authors in [8] predicted calving time using data from a RumiWatch noseband-sensor (ITIN + HOCH GmbH, Liestal, Switzerland) and a 3D-accelerometer. The authors stated that lying bouts increased and rumination decreased in primiparous and multiparous cows, respectively. Some studies have involved predicting calving time using activities such as trying to hide [17], moving the tail [18], walking aimlessly [19], turning the head towards the abdomen [20], reducing time spent in rumination [6], reducing time spent lying down, sniffing the ground [21], and frequently changing posture [22]. Figure 1 shows a variety of activities, such as standing up, lying down, holding up the tail, and turning the head backwards. 


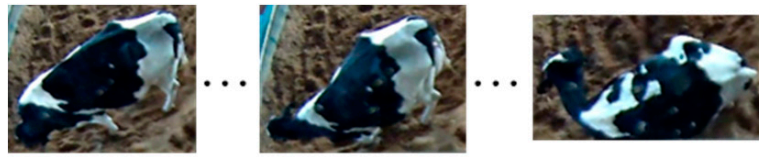

(a)

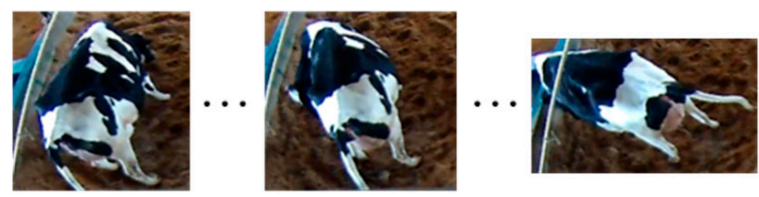

(c)

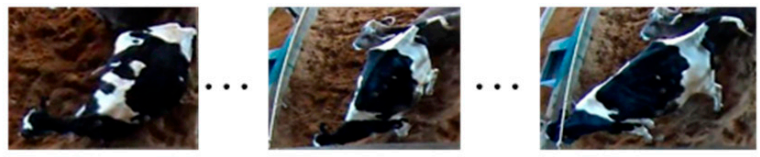

(b)

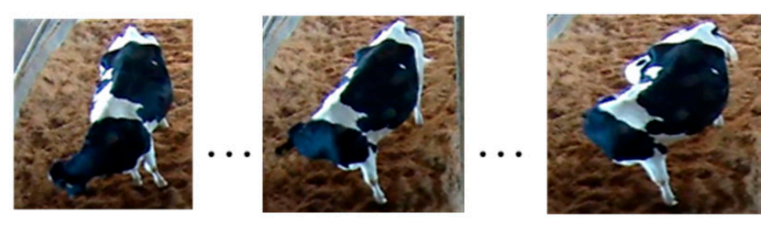

(d)

Figure 1. Bovine activities: (a) Lying down, (b) standing up, (c) holding up the tail, (d) turning the head backwards.

Now let us see what kinds of methods and techniques have been used for calving prediction in the environment of a maternity barn. Most prediction methods are developed through establishing a mathematical model. These methods are based on standard data analysis: Data preparation and logistic regression, artificial neural networks, and use of a support vector machine. Fenlon et al. created the four machine learning techniques: Multinomial regression, decision trees, random forests, and neural networks for predicting three levels of calving difficulty (unassisted, slight assistance, and considerable or veterinary assistance) [23]. Included in their analysis were variables related to parity, genetics, BCS, breed, previous calving experience, previous reproductive events, and the calf. Moreover, there are three machine learning techniques such as random forest, linear discriminant analysis, and neural network were used for calving time prediction and their method has developed a daily calving prediction model and bihourly calving models [7].

Most calving prediction methods developed so far require visual observations by experts in one way or another. All researchers attempted to develop automated systems that predict calving times, rather than require manual processes by farming personnel or veterinarians [24]. In our previous work [25], the analysis on cow's calving process is performed by using the motion features such as tail up, increasing movement, repeated transitions and so on. Sumi et al. proposed automatic cow behavior detection by using image processing and computer vision techniques to implement in cow calving monitoring system [26]. The frequency of standing bouts and lying bouts were considered as the variables to predict calving. To extract cow regions from input images recorded in delivery barns, the authors in [27] proposed a background modelling method first using a Temporal Average filter and then the Gaussian Average method for updating the background model. In order to analyze the behaviors of a cow, the system must detect the cow regions. In our previous paper [28], patterns of cow motions are analyzed to predict calving time. These patterns included transition states such as standing-to-lying and lying-to-standing. In this paper, we mainly propose a promising new integrated HMM based on behavior changes and the duration of time spent lying down when calving is imminent. The proposed HMM is a new approach in calving time prediction. Although many other approaches such as machine learning techniques haven been appeared, our approach is much easier and not much data are needed for the training process. The rest of the paper is organized as follows: Section 2 describes the main contributions of the paper related to the proposed methodology, and Section 3 provides the experimental results. We conclude the paper in Section 4.

\section{Proposed Dairy Cow Calving Time Prediction}

In this section, we propose an activity-integrated HMM to predict when calving will occur. Figure 2 provides an overview of the proposed model. The system is composed of two functional units: (1) Behavior classification and counting of each behavior, (2) the activity-integrated HMM Markov Model, as well as the final pipeline of the decisionmaking unit (results output). 

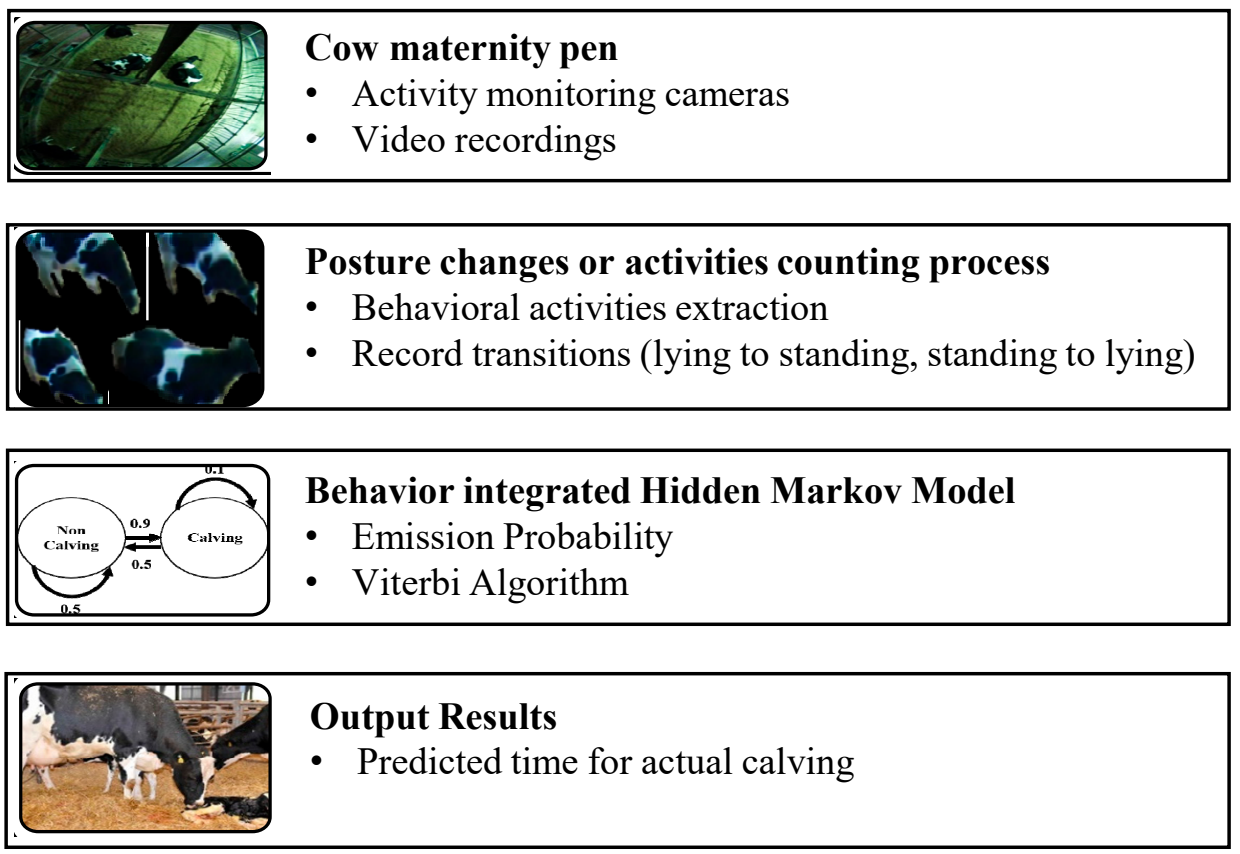

Figure 2. Overview of proposed dairy cow calving time prediction.

Video recordings were taken of cow behavior during the days and nights before actually calving. Our system focuses on behavior such as time spent lying down, and changes in posture such as bouts of changing position between lying down and standing up. In addition, we also recorded tail movements, and head turns. Such types of data are collected by human observers. In our proposed system, we use the terms standing bouts, referring to the transition from lying down to standing up, and lying bouts, referring to the transition from standing up to lying down. The step by step processes for our calving time prediction model are described in the following sub-sections.

\subsection{Activity Observation}

Generally, data on this behavior are collected three to seven days ahead of the expected calving time, defined as the cow's behavior, with each type of behavior serving as an independent variable. The behavior collected data for 3 days before calving is sufficient to make prediction while compared to behavior collected data for 7 days. Therefore, in our case, we only used data from 3 days prior to calving. Calving time is considered a dependent variable. In this paper, activities such as standing up, lying down and changes in posture are considered a prelude to calving. These behavior observations were performed on 25 cows by human observers.

\subsection{Data Summarization}

Video recordings for the behaviors of the individuals were made over a duration of three days before the expected calving dates. This paper, reports on the results of an experiment performed on 25 dairy heifers from the farm in Oita prefecture, Japan. The pregnant heifers were continuously video-monitored by a 360-degree GV-FER5700 camera (GeoVision Inc., Taiwan, China) located at the center of the barn providing the best possible view of the whole barn. The camera has a resolution of $2560 \times 2048$ pixels, recording at 30 frames per second.

The camera was placed $3 \mathrm{~m}$ above the floor in each loose housing calving pen. Cows were free to move about within a space measuring approximately $7 \times 7$ square meters, on a floor covered with sawdust for bedding. In our experiments, we collected data on 25 pregnant heifers, 19 Holstein first-calf heifers and 6 Brown-Swiss first-calf heifers, which calved from November to December in 2017. Parturitions were observed at ages between 21 and 26 months. These heifers became pregnant by embryo transfer. The recipient heifers 
were transferred in vivo-developed embryos obtained from Japanese black cows. The donor Japanese black cows were artificially inseminated with frozen-thawed semen from Japanese black bulls to collect embryos to transfer after superovulation treatment. No twin or triplet births occurred during this study. Group feeding system for two to four animals were used during this study depending on the timing of parturition of each heifer. They were fed with Total Mixed Ration (TMR) twice daily which was calculated depending on the prospected average milk yield ( $35 \mathrm{~kg} /$ day) after parturition and body weight estimated. Clean water and mineral supplements were available ad libitum during the entire period. Information on recording start time and calving data for the 25 cows are shown in Table 1.

Table 1. Calving data information for 25 pregnant heifers.

\begin{tabular}{|c|c|c|c|c|}
\hline \multirow{2}{*}{ ID } & \multicolumn{2}{|c|}{ Recording Started Date and Time } & \multicolumn{2}{|c|}{ Calving Date and Time } \\
\hline & $(\mathrm{mm} / \mathrm{dd} / \mathrm{yy})$ & $(\mathrm{h} / \mathrm{min} / \mathrm{s})$ & $(\mathrm{mm} / \mathrm{dd} / \mathrm{yy})$ & $(\mathrm{h} / \mathrm{min} / \mathrm{s})$ \\
\hline 1 & 11.29.2017 & $(00: 00: 00)$ & 12.02.2017 & $(12: 32: 50)$ \\
\hline 2 & 11.26.2017 & $(17: 10: 00)$ & 11.29.2017 & $(17: 10: 00)$ \\
\hline 3 & 11.26 .2017 & $(19: 35: 00)$ & 11.29 .2017 & $(19: 35: 00)$ \\
\hline 4 & 12.04 .2017 & $(10: 05: 00)$ & 12.07.2017 & $(10: 06: 35)$ \\
\hline 5 & 11.30.2017 & $(15: 10: 00)$ & 12.03.2017 & $(15: 10: 00)$ \\
\hline 6 & 11.30.2017 & $(21: 15: 00)$ & 12.03 .2017 & $(21: 15: 00)$ \\
\hline 7 & 12.04 .2017 & $(10: 10: 00)$ & 12.07.2017 & $(10: 13: 00)$ \\
\hline 8 & 12.04 .2017 & $(16: 05: 00)$ & 12.07.2017 & $(16: 09: 40)$ \\
\hline 9 & 12.04 .2017 & $(14: 00: 00)$ & 12.06.2017 & $(20: 10: 00)$ \\
\hline 10 & 12.11.2017 & $(06: 00: 00)$ & 12.14.2017 & $(05: 58: 50)$ \\
\hline 11 & 12.06 .2017 & $(10: 00: 00)$ & 12.08 .2017 & $(03: 25: 00)$ \\
\hline 12 & 12.12.2017 & $(04: 50: 00)$ & 12.15 .2017 & $(04: 53: 09)$ \\
\hline 13 & 12.07.2017 & $(17: 20: 00)$ & 12.10.2017 & $(17: 20: 00)$ \\
\hline 14 & 12.13.2017 & (21:00:00) & 12.16.2017 & $(21: 03: 29)$ \\
\hline 15 & 12.16.2017 & $(21: 55: 00)$ & 12.19.2017 & $(21: 55: 00)$ \\
\hline 16 & 12.14.2017 & $(17: 15: 00)$ & 12.17.2017 & $(17: 19: 20)$ \\
\hline 17 & 12.17.2017 & $(06: 10: 00)$ & 12.20 .2017 & $(06: 10: 00)$ \\
\hline 18 & 12.14.2017 & $(16: 15: 00)$ & 12.17.2017 & $(16: 17: 12)$ \\
\hline 19 & 12.17.2017 & $(09: 50: 50)$ & 12.20 .2017 & $(09: 50: 00)$ \\
\hline 20 & 12.15.2017 & $(01: 25: 00)$ & 12.18.2017 & $(01: 25: 21)$ \\
\hline 21 & 12.17.2017 & $(12: 15: 00)$ & 12.20 .2017 & $(12: 15: 00)$ \\
\hline 22 & 12.09 .2017 & $(17: 15: 00)$ & 12.12.2017 & $(17: 15: 00)$ \\
\hline 23 & 12.01.2017 & $(10: 25: 00)$ & 12.04 .2017 & $(10: 25: 18)$ \\
\hline 24 & 12.03.2017 & $(02: 40: 00)$ & 12.06 .2017 & $(02: 41: 22)$ \\
\hline 25 & 11.29.2017 & $(00: 30: 00)$ & 12.02 .2017 & $(00: 30: 00)$ \\
\hline
\end{tabular}

The categories of behavior described in Table 2 are used to observe the activities of heifers over the last $72 \mathrm{~h}$ before delivery. Here we assume that the delivery time extends to the moment when the calf was fully expelled. These observations were recorded using the instantaneous sampling recording rule. The camera started video recording every $5 \mathrm{~min}$, and the time spent on each was aggregated on an hourly basis as described in Table 3. 
Table 2. Activity variable descriptions.

\begin{tabular}{clc}
\hline Variable Name & Unit Measure & Descriptions \\
\hline Lying Time & Minute/Interval & $\begin{array}{c}\text { The time in minutes that a cow has spent } \\
\text { lying with in a predefined interval }\end{array}$ \\
\hline Standing Time & Minute/Interval & $\begin{array}{c}\text { The time in minutes that a cow has spent } \\
\text { standing with in a predefined interval }\end{array}$ \\
\hline Lying Bouts & Number/Interval & $\begin{array}{c}\text { The number of transitions from standing to } \\
\text { lying during the interval }\end{array}$ \\
\hline Standing Bouts & Number/Interval & $\begin{array}{c}\text { The number of transitions from lying to } \\
\text { standing during the interval }\end{array}$ \\
\hline
\end{tabular}

Table 3. Sample posture changes data in experiment.

\begin{tabular}{|c|c|c|c|c|c|c|c|c|}
\hline \multicolumn{9}{|c|}{ Cow ID 1} \\
\hline Time & $\begin{array}{l}\text { Posture } \\
\text { Changes }\end{array}$ & $\begin{array}{c}\text { Activity } \\
\text { Level }\end{array}$ & Time & $\begin{array}{l}\text { Posture } \\
\text { Change }\end{array}$ & $\begin{array}{l}\text { Activity } \\
\text { Level }\end{array}$ & Time & $\begin{array}{l}\text { Posture } \\
\text { Change }\end{array}$ & $\begin{array}{c}\text { Activity } \\
\text { Level }\end{array}$ \\
\hline-72 & 2 & Mid & -48 & 2 & Mid & -24 & 3 & Mid \\
\hline-71 & 2 & Mid & -47 & 4 & High & -23 & 3 & Mid \\
\hline-70 & 5 & High & -46 & 2 & Mid & -22 & 4 & High \\
\hline-69 & 6 & High & -45 & 3 & Mid & -21 & 2 & Mid \\
\hline-68 & 1 & Low & -44 & 1 & Low & -20 & 4 & High \\
\hline-67 & 2 & Mid & -43 & 2 & Mid & -19 & 2 & Mid \\
\hline-66 & 1 & Low & -42 & 1 & Low & -18 & 2 & Mid \\
\hline-65 & 0 & Low & -41 & 0 & Low & -17 & 0 & Low \\
\hline-64 & 0 & Low & -40 & 1 & Low & -16 & 0 & Low \\
\hline-63 & 2 & Mid & -39 & 2 & Mid & -15 & 0 & Low \\
\hline-62 & 2 & Mid & -38 & 2 & Mid & -14 & 0 & Low \\
\hline-61 & 2 & Mid & -37 & 1 & Low & -13 & 4 & High \\
\hline-60 & 2 & Mid & -36 & 4 & High & -12 & 2 & Mid \\
\hline-59 & 1 & Low & -35 & 1 & Low & -11 & 0 & Low \\
\hline-58 & 2 & Mid & -34 & 2 & Mid & -10 & 1 & Low \\
\hline-57 & 2 & Mid & -33 & 1 & Low & -9 & 1 & Low \\
\hline-56 & 1 & Low & -32 & 0 & Low & -8 & 2 & Mid \\
\hline-55 & 0 & Low & -31 & 0 & Low & -7 & 2 & Mid \\
\hline-54 & 0 & Low & -30 & 0 & Low & -6 & 2 & Mid \\
\hline-53 & 0 & Low & -29 & 1 & Low & -5 & 6 & High \\
\hline-52 & 1 & Low & -28 & 4 & High & -4 & 2 & Mid \\
\hline-51 & 1 & Low & -27 & 2 & Mid & -3 & 2 & Mid \\
\hline-50 & 2 & Mid & -26 & 3 & Mid & -2 & 5 & High \\
\hline-49 & 1 & Low & -25 & 0 & Low & -1 & 13 & High \\
\hline
\end{tabular}

L: Low, M: Medium, H: Height.

The data used in our experiment were collected by human observers through video monitoring of individual heifers in the calving pen. Standing bouts (changing from lying to standing) and of lying bouts (from standing to lying) were counted to determine the number of posture changes from the video sequences. We then obtain the count of posture changes by combining the number of standing bouts and lying bouts every hour. Activities related to standing include standing still, walking and eating, and those related to lying include lying while inactive, and ruminating while lying.

\subsection{Integrated Hidden Markov Model for Calving Time Prediction}

HMM is a class of statistical modeling for sequential data, in most instances related to systems evolving over time. The system of interest is modeled using a state process or system process which evolves dynamically such that future states depend on the current state. The posture changes before calving can naturally be described by such a process evolved over time. Thus, in the process of predicting calving time, we assume that the 
system includes two types of states, non-calving (NC) state and calving (C) state which can be difficult to observe directly but that can be uncovered by using some information about non-calving state.

Activity data collected as described above is integrated into a HMM to predict when calving will occur. This model includes two hidden states to discover: NC and C. Our objective is to discover the time $\mathrm{T}$ at which calving occurs. Although these two hidden states are not directly observable, we can observe activities associated with these states in the days preceding a calving event. The probability of an observed activity being related to a hidden state is known as an emission probability.

Without loss of generality, as a univariate activity (say changes in postures), the number of changes in postures can be divided into three levels namely Low (L), Medium $(\mathrm{M})$, and High (H). To make the problem specific, the levels of posture changes will be defined as follows. Suppose the collected sequence of posture changes is $x_{1}, x_{2}, x_{3}, \ldots, x_{N}$, where $N$ stands for time (can be minute, hour or any duration). First calculate the sample mean $(\mu)$ and sample standard deviation $(\sigma)$. Definitions of Activity Levels are as follows:

1. If the observed value for posture changes is less than the sample mean $(\mu)$ then the activity is at a low level, and denoted by $L$.

2. If the observed value for posture changes lies between $(\mu)$ and $(\mu+\sigma)$ then the activity is at a medium level, and denoted by $M$.

3. If the observed value for posture changes is greater than $(\mu+\sigma)$ then the activity is at a high level, and denoted by $H$.

For each of two states (NC, C), the defined three levels (L, M, H) are observable, and their corresponding probabilities will become the emission probabilities in the HMM. Thus, the proposed calving time prediction model can be described as shown in Figure 3.

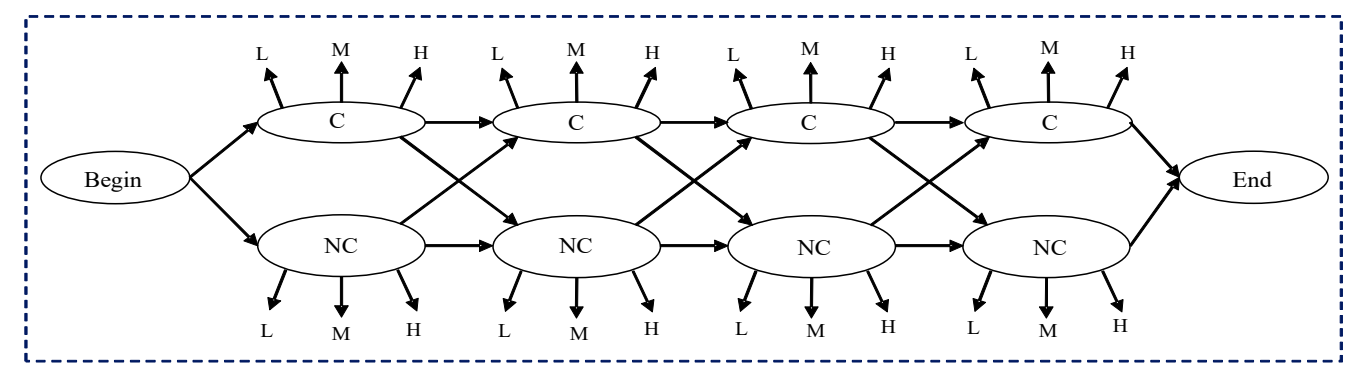

Figure 3. Illustration of Integrated Hidden Markov Calving Time Prediction Model.

Now we summarize the prediction model into usual notation of HMM.

$$
\mathrm{A}=\left[\begin{array}{ll}
a_{11} & a_{12} \\
a_{21} & a_{22}
\end{array}\right]
$$

where $a_{11}=$ transition probability from non-calving state to non-calving state,

$a_{12}=$ transition probability from non-calving state to calving state,

$a_{21}=$ transition probability from calving state to non-calving state,

$a_{22}=$ transition probability from calving state to calving state.

We assume that the initial probabilities for the states are given by:

$$
\begin{gathered}
\Pi=\left[\begin{array}{ll}
\Pi_{1} & \Pi_{2}
\end{array}\right], \\
\Pi_{1}+\Pi_{2}=1
\end{gathered}
$$

where, $\Pi_{1}=$ probability of non-calving,

$\Pi_{2}=$ probability of calving

The Low, Median, and High activity levels (L, M, H) are observable states which we can learn from the video sequences. The corresponding probabilities of $\mathrm{L}, \mathrm{M}$, and $\mathrm{H}$ are 
known as emission probabilities. In a matrix form, we denote emission probabilities as B. In our case the emission probabilities will derive from the activity level data and denoted by $B$ as follows:

$$
\mathrm{B}=\left[\begin{array}{ccc}
P(\mathrm{~L} \mid \mathrm{NC}) & P(\mathrm{M} \mid \mathrm{NC}) & P(\mathrm{H} \mid \mathrm{NC}) \\
P(\mathrm{~L} \mid \mathrm{C}) & P(\mathrm{M} \mid \mathrm{C}) & P(\mathrm{H} \mid \mathrm{C})
\end{array}\right] .
$$

In formal notation, the complete HMM becomes as follows:

$$
\lambda=(\mathrm{A}, \mathrm{B}, \Pi) .
$$

The most likely state was then calculated using transition matrix A and emission probability matrix B from the fitted logistic regression model using the Viterbi algorithm. The Viterbi algorithm is a recursive method to calculate the most likely path of hidden states given observed probabilities and state transition probabilities.

\subsection{Methodology Implementation Procedure}

The experimental videos were collected for 25 heifers. From these videos, posture changes were then counted, referring to changes from lying to standing, and from standing to lying. We organized the data on an hourly basis. The sample data is shown in Table 3. In our paper, we have utilized cow behavioral observations such as posture changes done by human observers for $72 \mathrm{~h}$ video before giving birth.

The sample mean and standard deviation of the frequency of posture changes are calculated from columns 2, 5, and 8 in Table 3. Table 4 shows the results for mean and standard deviation. To define the activity levels, the numbers for posture changes in the columns $(2,5,8)$ are compared with the values of $\mu$ and $\mu+\sigma$ described in Table 3 . Then, we obtain the activity levels for the columns $(3,6,9)$ in Table 3 :

Table 4. Sample mean and standard deviation.

\begin{tabular}{cl}
\hline Sample Mean $\mu$ of posture change frequency & 1.931 \\
\hline Standard Deviation $\sigma$ of posture change frequency & 1.967 \\
\hline$(\mu+\sigma)$ & 3.897 \\
\hline$(\mu+2 \sigma)$ & 5.864 \\
\hline
\end{tabular}

The activity levels are defined as follows:

- $\quad \mathrm{L}: n<\mu$,

- $\mathrm{M}: \mu<n<\mu+\sigma$,

- $\mathrm{H}: n>\mu+\sigma$

where, $n=$ posture changes, $\mu=1.931$ and $\mu+\sigma=3.897$.

The co-occurrence matrix for $\mathrm{NC}$ and $\mathrm{C}$ states are calculated from activity levels $(\mathrm{L}$, $\mathrm{M}$ and $\mathrm{H}$ ) in data collected over $72 \mathrm{~h}$ data as seen in columns 3, 6, and 9 from Table 3. We then count the number of occurrences of the combinations $(\mathrm{L}, \mathrm{L}),(\mathrm{L}, \mathrm{M}),(\mathrm{L}, \mathrm{H}), \ldots,(\mathrm{H}, \mathrm{H})$, totaling 9 possible combinations, and obtaining a $3 \times 3$ co-occurrence matrix for $\mathrm{NC}$ and $\mathrm{C}$ state. The sequence of labels for $\mathrm{L}, \mathrm{M}$ and $\mathrm{H}$ from Table 3 can be seen as shown in Figure 4.

\begin{tabular}{|c|c|c|c|c|c|c|c|c|}
\multicolumn{1}{c}{$60 \mathrm{hrs}$ (For Non-Calving Co-Occurrence Matrix) } & \multicolumn{3}{c|}{$12 \mathrm{hrs}$ (For Calving Co-Occurrence Matrix) } \\
\hline Time & -72 & -71 & $\ldots$ & -13 & -12 & -11 & $\ldots$ & -1 \\
\hline Level & $\mathrm{M}$ & $\mathrm{M}$ & $\ldots$ & $\mathrm{H}$ & $\mathrm{M}$ & $\mathrm{L}$ & $\ldots$ & $\mathrm{H}$ \\
\hline
\end{tabular}

Figure 4. Sequence of Activity Level.

In order to derive the co-occurrence matrices for $\mathrm{NC}$ and $\mathrm{C}$, we first assume that, the first $60 \mathrm{~h}$ to be a NC state and the final $12 \mathrm{~h}$ to be a $\mathrm{C}$ state. 
For NC states, the co-occurrence matrix is given by:

$$
\mathrm{NC}=\left[\begin{array}{ccc}
16 & 9 & 3 \\
10 & 10 & 4 \\
2 & 4 & 1
\end{array}\right]
$$

And for $\mathrm{C}$ state, the co-occurrence matrix is:

$$
C=\left[\begin{array}{lll}
2 & 1 & 0 \\
1 & 3 & 2 \\
0 & 1 & 1
\end{array}\right] .
$$

By normalizing rows of each co-occurrence matrix $\mathrm{NC}$ and $\mathrm{C}$, we obtain the corresponding probability matrices, respectively denoted by $\mathrm{P}$ and $\mathrm{Q}$ for non-calving and calving states.

$$
\begin{aligned}
& P=\left[\begin{array}{lll}
0.571 & 0.321 & 0.107 \\
0.416 & 0.416 & 0.167 \\
0.286 & 0.571 & 0.143
\end{array}\right] \\
& Q=\left[\begin{array}{lll}
0.667 & 0.333 & 0.000 \\
0.167 & 0.500 & 0.333 \\
0.000 & 0.500 & 0.500
\end{array}\right]
\end{aligned}
$$

We then calculate the stationary distributions by solving the above equations of $\mathrm{P}$ and Q. We obtain the stationary distribution for $P$ as $(0.475,0.393,0.135)$, and the stationary distribution for $\mathrm{Q}$ as $(0.231,0.462,0.308)$. These two distributions will be used as emission probabilities $\mathrm{B}$ for $\mathrm{NC}$ and $\mathrm{C}$ states, respectively. Also, from Table 3 , we obtain the transition probability matrix A. The illustration of state diagram for $\mathrm{NC}$ and $\mathrm{C}$ is shown in Figure 5.

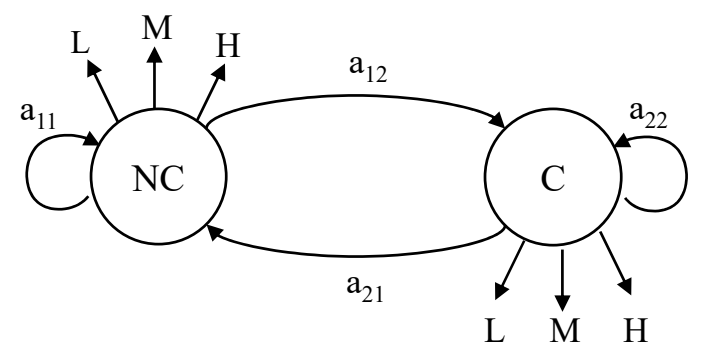

Figure 5. The state diagram for non-calving (NC) state and calving (C).

Initially we consider the first $60 \mathrm{~h}$ as NC state and $\mathrm{C}$ state will begin in next one hour. The total time taken for NC to NC and NC to $C$ is $61 \mathrm{~h}$. The transition probability from NC to NC as $a_{11}(60 / 61=0.984)$ and NC to $C$ as $a_{12}(1 / 61=0.016)$. In similar ways, the remaining $12 \mathrm{~h}$ is in $\mathrm{C}$ state and it will to NC state in next one hour. The transition probability from $C$ to NC as $a_{21}(1 / 13=0.077)$ and $C$ to $C$ as $a_{22}(12 / 13=0.923)$. The transition probability matrix for the two Hidden States: NC and C states, shown as follows:

$$
\mathrm{A}=\left[\begin{array}{ll}
0.984 & 0.016 \\
0.077 & 0.923
\end{array}\right]
$$

Now the HMM is completely defined with transition matrix A. The emission probability matrix $B$ from stationary distributions is

$$
\mathrm{B}=\left[\begin{array}{lll}
0.472 & 0.393 & 0.135 \\
0.231 & 0.462 & 0.308
\end{array}\right]
$$

Here, the initial probability to be considered as $\Pi=[0.5,0.5]$. 


\section{Experimental Results}

In order to obtain the experimental results, we apply the Viterbi algorithm to the HMM developed in Section 2. Consequently, we have the most likely state sequence for a given observed sequence as shown in Table 5.

Table 5. The most likely state sequence.

\begin{tabular}{|c|c|c|c|c|c|c|c|}
\hline Actual Time & $\begin{array}{c}3 \mathrm{~h} \text { Interval } \\
1-24\end{array}$ & Activity & States & Actual Time & $\begin{array}{c}3 \mathrm{~h} \text { Interval } \\
1-24\end{array}$ & Activity & States \\
\hline-72 & -24 & $\mathrm{~L}$ & $\mathrm{NC}$ & -36 & -12 & $\mathrm{~L}$ & $\mathrm{NC}$ \\
\hline-69 & -23 & $\mathrm{~L}$ & $\mathrm{NC}$ & -33 & -11 & $\mathrm{~L}$ & $\mathrm{NC}$ \\
\hline-66 & -22 & $\mathrm{~L}$ & $\mathrm{NC}$ & -30 & -10 & $\mathrm{~L}$ & $\mathrm{NC}$ \\
\hline-63 & -21 & $\mathrm{~L}$ & $\mathrm{NC}$ & -27 & -9 & $\mathrm{~L}$ & $\mathrm{NC}$ \\
\hline-60 & -20 & $\mathrm{~L}$ & $\mathrm{NC}$ & -24 & -8 & M & $\mathrm{NC}$ \\
\hline-57 & -19 & $\mathrm{~L}$ & $\mathrm{NC}$ & -21 & -7 & $\mathrm{~L}$ & $\mathrm{NC}$ \\
\hline-54 & -18 & $\mathrm{~L}$ & $\mathrm{NC}$ & -18 & -6 & $\mathrm{~L}$ & $\mathrm{NC}$ \\
\hline-51 & -17 & $\mathrm{~L}$ & $\mathrm{NC}$ & -15 & -5 & $\mathrm{~L}$ & $\mathrm{NC}$ \\
\hline-48 & -16 & $\mathrm{~L}$ & $\mathrm{NC}$ & -12 & -4 & $\mathrm{~L}$ & $\mathrm{NC}$ \\
\hline-45 & -15 & $\mathrm{~L}$ & $\mathrm{NC}$ & -9 & -3 & $\mathrm{~L}$ & $\mathrm{NC}$ \\
\hline-42 & -14 & $\mathrm{~L}$ & $\mathrm{NC}$ & -6 & -2 & $\mathrm{M}$ & $\mathrm{NC}$ \\
\hline-39 & -13 & $\mathrm{~L}$ & $\mathrm{NC}$ & -3 & -1 & $\mathrm{H}$ & C \\
\hline
\end{tabular}

L: Low, M: Medium, H: Height, NC: Non-calving, C: Calving.

The last row of Table 5 showed that the calving occurs during last three hours, which agrees with the time of the actual occurrence of calving. Among these 25 heifers, we randomly selected 15 heifers to estimate HMM parameters, and testing proceeded on the remaining 10 heifers. The performance analysis on testing data of 10 heifers is shown in Table 6. Overall, our system achieved the average sensitivity of $91.05 \%$ and average precision of $93.28 \%$ on testing data.

Table 6. Performance analysis for 10 heifers.

\begin{tabular}{ccc}
\hline No. & Sensitivity (\%) & Precision (\%) \\
\hline 1 & 91.30 & 95.45 \\
2 & 86.96 & 95.24 \\
3 & 90.63 & 87.88 \\
4 & 95.83 & 100 \\
5 & 91.67 & 100 \\
6 & 90.48 & 86.36 \\
7 & 91.67 & 100 \\
8 & 91.67 & 100 \\
9 & 85 & 80.95 \\
10 & 95.24 & 86.96 \\
\hline Average & 91.05 & 93.28 \\
\hline
\end{tabular}

The actual time of calving lies one standard deviation away from the sample. Thus, the error term is absolute value of difference $(3-(\mu+\sigma))=0.897$. Therefore, the error percentage is $(0.897) / 3$ which is equal to 0.299 . This gives a mean square error of $(0.299)^{2}=$ 0.089401 . We can conclude that the overall accuracy rate is $(1-0.089401) \times 100=91.0599$, a little over $91 \%$.

\section{Conclusions}

We propose an activity-integrated HMM for predicting when calving will occur. For developing our method in this study, we only used data for posture changes such as lying bouts and standing bouts among many other features such as tail up and increasing movements. We expect that prediction accuracy will improve by using data for additional activities such as time spent lying down, rumination, tail movements, and head movements. To conduct the real time calving prediction system, real time cow identification, activity 
observation and prediction model will then be combined to become a complete system. Much research remains to be done in the future, by collecting and testing additional data.

Author Contributions: Conceptualization: K.S., T.T.Z. and P.T.; methodology, K.S., S.Z.M. and T.T.Z.; software, S.Z.M.; validation, T.T.Z., P.T., I.K. and Y.H.; resources, I.K. and Y.H.; writing-original draft preparation, K.S., S.Z.M., T.T.Z. and P.T.; writing-review \& editing, K.S., S.Z.M. and P.T.; visualization, P.T.; supervision, T.T.Z. and P.T. All authors have read and agreed to the published version of the manuscript.

Funding: This work was supported in part by JSPS KAKENHI Grant Number 17K08066, SCOPE: Strategic and Communications R\&D Promotion Program (Grant No. 172310006) and Honkawa Ranch Research Grant 2019-A-01.

Institutional Review Board Statement: Ethical review and approval were waived for this study, due to no enforced nor uncomfortable restriction to the animals during the study period. The image data of calving process used for analysis in this study were collected by an installed camera without disturbing natural parturient behavior of animals and routine management of the farm.

Informed Consent Statement: Not applicable.

Data Availability Statement: The data presented in this study are available on request from the corresponding author. The data are not publicly available due to patent pending.

Acknowledgments: We thank K. Honkawa, D.V.M. for giving every convenience of the study in the ranch and his valuable advice.

Conflicts of Interest: The authors declare no conflict of interest.

\section{References}

1. Mee, J.F. Why Do So Many Calves Die on Modern Dairy Farms and What Can We Do about Calf Welfare in the Future? Animal 2013, 3, 1036-1057. [CrossRef] [PubMed]

2. Streyl, D.; Sauter-Louis, C.; Braunert, A.; Lange, D.; Weber, F.; Zerbe, H. Establishment of a standard operating procedure for predicting the time of calving in cattle. J. Vet. Sci. 2011, 12, 177-185. [CrossRef] [PubMed]

3. Mee, J.F.; Berry, D.; Cromie, A. Risk factors for calving assistance and dystocia in pasture-based Holstein-Friesian heifers and cows in Ireland. Vet. J. 2011, 187, 189-194. [CrossRef] [PubMed]

4. Jensen, M.B. Behavior around the time of calving in dairy cows. Appl. Anim. Behav. Sci. 2012, 139, 195-202. [CrossRef]

5. Mee, J.; English, L. Prediction of Onset of Calving from Tail Elevation-Preliminary Evaluation of a Novel Biosensor; Animal \& Grassland Research and Innovation Centre, Moorepark, Fermoy Co.: Cork, Ireland, July 2019; pp. 156-157.

6. Maltz, E.; Antler, A. A practical way to detect approaching calving of the dairy cow by a behaviour sensor. In Proceedings Precision Livestock Farming; Wageningen Academic Publishers: Skiathos, Greece, 2007; pp. 141-146.

7. Borchers, M.R.; Chang, Y.M.; Proudfoot, K.L.; Wadsworth, B.A.; Stone, A.E.; Bewley, J.M. Machine-learning-based calving prediction from activity, lying, and ruminating behaviors in dairy cattle. J. Dairy Sci. 2017, 100, 5664-5674. [CrossRef]

8. Fadul, M.; Bogdahn, C.; Alsaaod, M.; Hüsler, J.; Starke, A.; Steiner, A.; Hirsbrunner, G. Prediction of calving time in dairy cattle. Anim. Reprod. Sci. 2017, 187, 37-46. [CrossRef]

9. Lammoglia, M.A.; Bellows, R.A.; Short, R.E.; Bellows, S.E.; Bighorn, E.G.; Stevenson, J.S.; Randel, R.D. Body temperature and endocrine interactions before and after calving in beef cows. J. Anim. Sci. 1997, 75, 2526-2534. [CrossRef]

10. Miedema, H.M.; Cockram, M.S.; Dwyer, C.M.; Macrae, A.I. Changes in the behavior of dairy cows during the $24 \mathrm{~h}$ before normal calving compared with behavior during late pregnancy. Appl. Anim. Behav. Sci. 2011, 131, 8-14. [CrossRef]

11. Ouellet, V.; Vasseur, E.; Heuwieser, W.; Burfeind, O.; Maldague, X.; Charbonneau, É. Evaluation of calving indicators measured by automated monitoring devices to predict the onset of calving in Holstein dairy cows. J. Dairy Sci. 2016, 99, 1539-1548. [CrossRef]

12. Higaki, S.; Koyama, K.; Sasaki, Y.; Abe, K.; Honkawa, K.; Horii, Y.; Minamino, T.; Mikurino, Y.; Okada, H.; Miwakeichi, F.; et al. Technical note: Calving prediction in dairy cattle based on continuous measurements of ventral tail base skin temperature using supervised machine learning. J. Dairy Sci. 2020, 103, 8535-8540. [CrossRef]

13. Saint-Dizier, M.; Chastant-Maillard, S. Methods and on-farm devices to predict calving time in cattle. Vet. J. 2015, 205, 349-356. [CrossRef] [PubMed]

14. Rutten, C.J.; Kamphuis, C.; Hogeveen, H.; Huijps, K.; Nielen, M.; Steeneveld, W. Sensor data on cow activity, rumination, and ear temperature improve prediction of the start of calving in dairy cows. Comput. Electron. Agric. 2017, 132, 108-118. [CrossRef]

15. Proudfoot, K.; Jensen, M.; Weary, D.; Von Keyserlingk, M.A. Dairy cows seek isolation at calving and when ill. J. Dairy Sci. 2014, 97, 2731-2739. [CrossRef] [PubMed]

16. Schirmann, K.; Chapinal, N.; Weary, D.; Vickers, L.; Von Keyserlingk, M. Short communication: Rumination and feeding behavior before and after calving in dairy cows. J. Dairy Sci. 2013, 96, 7088-7092. [CrossRef] [PubMed] 
17. Huzzey, J.; Von Keyserlingk, M.; Weary, D. Changes in Feeding, Drinking, and Standing Behavior of Dairy Cows During the Transition Period. J. Dairy Sci. 2005, 88, 2454-2461. [CrossRef]

18. Rice, C.A.; Eberhart, N.L.; Krawczel, P.D. Prepartum lying behavior of holstein dairy cows housed on pasture through parturition. Animals 2017, 7, 32. [CrossRef] [PubMed]

19. Mee, J. Managing the dairy cow at calving time. Vet. Clin. N. Am. Food Anim. Pract. 2004, 20, 521-546. [CrossRef]

20. Cangar, O.; Leroy, T.; Guarino, M.; Vranken, E.; Fallon, R.; Lenehan, J.; Mee, J.; Berckmans, D. Automatic real-time monitoring of locomotion and posture behavior of pregnant cows prior to calving using online image analysis. Comput. Electron. Agric. 2008, 64, 53-60. [CrossRef]

21. Ferreira, A.G.; Henrique, D.S.; Vieira, R.A.; Maeda, E.M.; Valotto, A.A. Fitting mathematical models to lactation curves from holstein cows in the southwestern region of the state of Parana, Brazil. Anais Acad. Bras. Ciências 2015, 87, 503-517. [CrossRef]

22. Burfeind, O.; Suthar, V.; Voigtsberger, R.; Bonk, S.; Heuwieser, W. Validity of prepartum changes in vaginal and rectal temperature to predict calving in dairy cows. J. Dairy Sci. 2011, 94, 5053-5061. [CrossRef]

23. Fenlon, C.; O'Grady, L.; Mee, J.F.; Butler, S.T.; Doherty, M.L.; Dunnion, J. A comparison of 4 predictive models of calving assistance and difficulty in dairy heifers and cows. J. Dairy Sci. 2017, 100, 9746-9758. [CrossRef] [PubMed]

24. Marchesi, G.; Leonardi, S.; Tangorra, F.M.; Calcante, A.; Beretta, E.; Pofcher, E.; Lazzari, M. Evaluation of an electronic sys-tem for automatic calving detection on a dairy farm. Anim. Product. Sci. 2013, 53, 1112-1114. [CrossRef]

25. Sumi, K.; Zin, T.T.; Kobayashi, I.; Horii, Y. A Study on Cow Monitoring System for Calving Process. In Proceedings of the IEEE 6th Global Conference on Consumer Electronics (GCCE 2017), Nagoya, Japan, 24-27 October 2017; pp. 379-380. [CrossRef]

26. Sumi, K.; Zin, T.T.; Kobayashi, I.; Horii, Y. Framework of Cow Calving Monitoring System Using a Single Depth Camera. In Proceedings of the 2018 International Conference on Image and Vision Computing New Zealand (IVCNZ), Auckland, New Zealand, 19-21 November 2018. [CrossRef]

27. Zin, T.T.; Mar, C.C.; Sumi, K. Background Modelling Using Temporal Average Filter and Running Gaussian Average. In Proceedings of the International Workshop on Frontiers of Computer Vision (IW-FCV), Ibusuki, Japan, 20-22 February 2020.

28. Zin, T.T.; Maung, S.Z.M.; Tin, P.; Horii, Y. Feature Detection and Classification of Cow Motion for Predicting Calving time. In Proceedings of the 2020 IEEE 9th Global Conference on Consumer Electronics (GCCE), Kobe, Japan, 13-16 October 2020; pp. 305-306. 